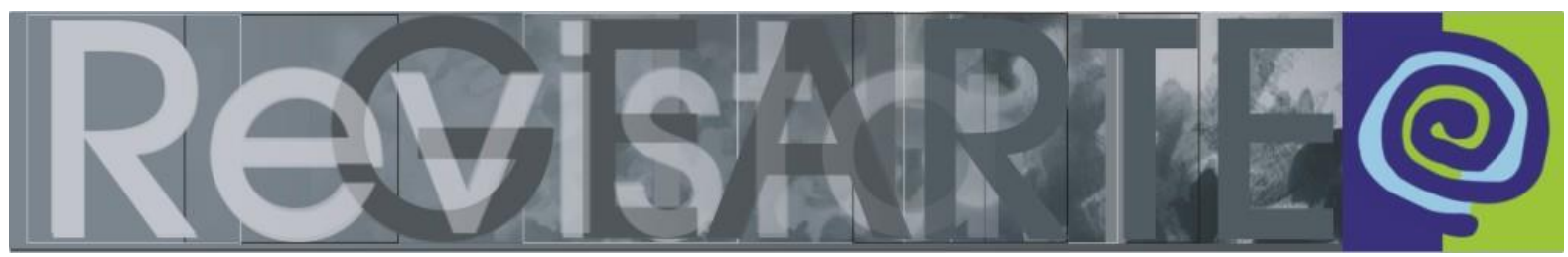

e-ISSN 2357-9854

\title{
Abordagem canibal, antropofagia de conceitos
}

\author{
Paola Zordan (Universidade Federal do Rio Grande \\ do Sul — UFRGS, Porto Alegre/RS, Brasil)
}

RESUMO - Abordagem canibal, antropofagia de conceitos - Ao afirmar que a prática é imanente à conceptualização, este estudo mostra a antropofagia na criação de abordagens para o Ensino da Arte, especialmente nas construções teóricas de Ana Mae Barbosa. Recorta diversos conceitos de arte enunciados por licenciandos participantes da pesquisa, apresentando canibalizações discursivas de diversas perspectivas. Essas são pensadas com a geofilosofia de Deleuze e Guattari, autores usados no texto para articular conceitos de arte com o amplo processo envolvido em sua compreensão.

PALAVRAS-CHAVE

Antropofagia. Abordagem Triangular. Geofilosofia. Concepções de arte.

ABSTRACT - Cannibal approach, anthropophagy of concepts - Affirming the practice is immanent to conceptualization, this study introduce anthropophagic ways that create approaches to art education, especially theoretical constructions of Ana Mae Barbosa. Extracts severals art concepts enunciated by students in research groups that shows a cannibal speech around several perspectives. Uses the Deleuze and Guattarigeophilosophy to think the broad process for comprises art.

KEYWORDS

Anthropophagy. Triangular Approach. Geophylosophy. Art conceptions.

\section{Pensamento da terra}

Deleuze e Guattari criaram a geofilosofia, cujo chão conceitual compreende múltiplos movimentos, desterritorializações e reterritorializações. Trabalhando com conceitos implicados no estudo do que chamaram "território", plano que reúne os elementos referenciais, existenciais e sociais, onde todas as concepções devêm de uma multiplicidade de matérias, os conceitos, adquiridos por hábito, constituem territórios, possuem seus movimentos, relações de conjunto e vizinhança, contágios e conflitos, absorções, banimentos. Criar um conceito é invocar um território, uma nova terra e um povo que não existe ainda, um povo por vir, que os autores dizem advir dos "trópicos".

Para Suely Rolnik, a antropofagia é uma palavra-senha, máquina de guerra (DELEUZE; GUATTARI, 1997) que descortina o plano de consistência potencialmente disponível na cultura brasileira. Alimento que preserva a vibração invisível do corpo, a vitalidade antropófaga é um "efeito de encontros", aquela que trai as máscaras 
vigentes para que os afetos possam passar, autorizar e liberar o óbvio, deixar a vida desfilar (ROLNIK, 1989, p. 262-263). Pensamento canibal, a antropofagia acolhe multiplicidades, tribos e bandos, num fascínio que nada tem a ver com o exótico, mas que encanta os intelectuais estrangeiros. Guattari, ao visitar o Brasil, observou que "em matéria de índios, metropolitanos ou tupiniquins" os europeus são subdesenvolvidos. Esta potência nativa, selvagem, configurou, aos olhos de Guattari, o Brasil dos anos 1980 como o país das "revoluções moleculares" (GUATTARI; ROLNIK, 1999).

Entre tantas ações micro revolucionárias, destacamos as vitais canibalizações culturais de Ana Mae Barbosa, as quais revolucionaram o ensino de Artes no Brasil, e que, de acordo com a própria, contornam a "dependência cultural" típica de países como o nosso, apresentando uma "maneira de ser criativo" (BARBOSA, 1998, p. 119) frente às desigualdades, misérias e outras mazelas culturais. Num país de "criadores multidisciplinares" (BARBOSA, 1998, p. 147) como Mário e Oswald de Andrade, Ana Mae, dentro de um processo dinâmico e dialogal, constrói uma abordagem de múltiplas referências e aberta a diversos enfoques a fim de resolver os inúmeros problemas detectados entre a Arte e seu ensino. Antes de perguntar "quem deglute quem" (BARBOSA, 1998, p. 33), observa que o século XXI sugere "operações mais complexas do que a sedutora ideia modernista do canibalismo/antropofagia" (BARBOSA, 1998, p. 32). Para pensar a conceitualização prática do que vem a ser o sentido antropofágico presente em torno do ensino de Artes, trago alguns recortes investigativos e algumas considerações críticas a fim de pensarmos a formação acadêmica nas Artes Visuais dentro de sua atual complexidade. Os discursos, dentro desta digeridos e expressos pelos enunciados destacados no texto, são pensados em sua articulação com projetos em sala de aula e também quanto à criação poética que os permeia.

Junto aos enunciados que abaixo se apresentam, podemos perceber a absorção, ou, para usar as metáforas alimentares (KEMPINSKA,2016), a digestão de conceitos, criações que consistem planos de pensamento, seja o filosófico, seja o de composição artística. Partindo da premissa de que se ensina aquilo que se concebe como paisagem essencial para vida, a investigação que permeia este ensaio trata de 
discursos ${ }^{1}$ em torno da arte e seu ensino (ZORDAN, 2008), junto aos quais, a Abordagem Triangular está intensamente deglutida e digerida. "Única lei do mundo" (ANDRADE, 1928), a antropofagia nos une ${ }^{2}$.

\section{Conceitos para ARTE}

Primeiro contato entre a professora especializada de artes e alunos, muitos filhos de professores e intelectuais, do quinto ano do Ensino Fundamental, em uma escola de metrópole. A professora se apresenta, explica que desenvolverão trabalhos específicos, discursa sobre a importância da arte no desenvolvimento da civilização e pergunta para a turma: "desde quando vocês acham que a arte existe?" Dos 26 alunos, mais da metade, 18 ou 17 crianças, levantam os braços para responder. Há os hesitantes, que levantam e abaixam e os que levantam o braço já no decorrer das falas. Aleatoriamente, a professora vai apontando alunos, que dizem, com mínimas variações, que a arte existe desde o "tempo das cavernas", desde a "pré-história". A resposta que mais variou foi a de que a "arte existe desde que o homem é homem", mas de modo algum a professora se atreveu a perguntar quando foi mesmo que o homem se tornou homem. A partir da resposta dos alunos anuncia que irão estudar a arte desde a pré-história. O encontro segue com a solicitação de um desenho livre em uma folha de desenho tamanho ofício, cujo objetivo, de acordo com o que a professora diz para a pesquisadora, até então observando tudo ao fundo da sala, é sondar o desenvolvimento gráfico dos alunos. Enquanto a atividade se desenrola a pesquisadora caminha entre as classes. Ao aproximar-se de uma aluna, a quem a pesquisadora conhece de ambientes exteriores à escola, é chamada para escutar o seguinte: "Sabe, eu tive muita vergonha de dizer a minha resposta, porque ela era diferente e eu tive medo de errar. Eu acho que a arte existe desde sempre, desde que o mundo é mundo, não tem início e nem fim, entende? Tu, que vem lá da Universidade, acha que pensar isso é errado?" Tais palavras foram sussurradas, próxima ao rosto da pesquisadora, que explicou à menina de dez anos de idade que não era errado, apenas era uma concepção muito diferente, que talvez ela tivesse aprendido com o pai dela, leitor de Nietzsche, que via a arte para além das coisas do homem e da história da humanidade, de modo que nessa concepção a arte não é só o que o homem faz e que se ela tivesse dito aquilo, a turma poderia ter começado um debate interessante. A menina fala então, um pouco mais alto, "então tudo pode ser arte", ao que a pesquisadora completa, "depende do conceito de arte". A aluna pergunta: "e qual é o conceito certo de arte?", para ouvir que o que é certo "depende do contexto". Voltando a falar baixo, meio tímida, ela conclui, sob o olhar já desconfiado da professora frente à intromissão de quem estava no ambiente só para observar "quer dizer que se ninguém concorda comigo pode parecer que eu estou errada?", ao que a pesquisadora responde, já se afastando para voltar ao seu posto, "de jeito nenhum, pensar diferente não é estar errado, é apenas mais difícil".

Além desse recorte das inúmeras observações em sala de aula, aqui transcrito

\section{para introduzir a problemática conceituação da arte, extraímos algumas passagens e}

1 Embora $A$ arqueologia do saber não seja aqui referendada e não seja o caso, no presente texto, de explicar as ferramentas teoréticas, o conceito de enunciado usado neste ensaio opera com as problematizações da enunciação presente nos textos de Deleuze e Guattari, desenvolvidas à maneira de Michel Foucault.

2 O manifesto antropofágico escrito por Oswald de Andrade, em 1928, é erigido contra as religiões, os costumes, a psicanálise, os estados cadavéricos, as escleroses urbanas e a "baixa antropofagia" que se aglomera nos "pecados de catecismo: a inveja, a usura, a calúnia, o assassinato". Oswald convoca à absorção do "inimigo sacro" para transformá-lo em totem. Contra os tabus e a "moral da cegonha", conclama o barbarismo do "matriarcado de Pindorama". 
frases em conversas semiestruturadas, nas quais cada um dos participantes ${ }^{3}$ colocava aquilo que entendia como arte. Também eram incentivados a escreverem pequenos ensaios para exporem a questão inicial Qual a tua concepção de arte?, que ia sendo desdobrada a partir das respostas que surgiam. Embora se admita, junto com um dos participantes que, definir arte com palavras é uma tarefa difícil, talvez impossível, nos pautamos pela imanência dos conceitos de arte nas práticas educativas e poéticas do campo em questão. Junto a observações de aulas de artes na Escola Básica, 12 textos foram recebidos e seis conversas desenvolvidas. Deste material foram utilizados enunciados recorrentes, apresentando as conceptualizações que consistem nesse ensaio. A partir dessas fontes, pode-se dizer que há fortes absorções pelas quais professores em formação compreendem a arte: a expressão sentimentalista, a comunicação e a epistemologia e, em menor escala, a diferença culturalista. É possível detectar a articulação entre o culturalismo e o expressivismo advindas da construção discursiva dos livros de Ana Mae Barbosa, em especial a concepção de arte como cultura e expressão apresentada em Tópicos Utópicos. Sua abordagem noética, embora seja multifacetada e randômica, ganhou o nome "triangular" ao propor

3 Estes são 35 graduandos concluintes do curso de Licenciatura em Artes Visuais da UFRGS. As conversas se constituíram transversalmente em três turmas de 12, 18 e 15 alunos em situação de Estágio Docente, porém apenas 35 alunos assinaram o Termo de Consentimento para que suas falas pudessem ser transcritas. A faixa etária dos que participaram da pesquisa variava entre $21 \mathrm{e}$ 58 anos, sendo que a idade média fica em torno de 29 anos. Sete já haviam concluído o Bacharelado em outras ênfases das Artes Visuais e seis já haviam concluído outros cursos superiores (Ciências Contábeis, Farmácia, Letras, Licenciatura em Matemática), sendo que um já era bacharel em duas áreas distintas (Direito e Psicologia), entrando no curso com ingresso de diplomado. Somente sete alunos dedicavam-se exclusivamente ao curso, sendo que quatro trabalhavam, concomitantemente aos estágios, junto a pesquisas de Iniciação Científica. Cinco eram professores contratados do Estado, três professoras eram concursadas do Estado (duas em outras áreas e uma em Séries Iniciais) e uma efetiva, em outra área, no Município. Uma era professora em reconhecida oficina de artes do Estado e dois ministravam aulas particulares de pintura, sendo que somente estes possuíam ateliê. Três alunos desenvolviam atividades na área da publicidade, quatro estavam tentando desenvolver carreira artística, sendo que uma na área musical. Uma aluna estagiava na área cultural do município, uma trabalhava em instituição pública ministrando medicamentos para detentos, um aluno trabalhava na ação educativa de instituição cultural, dois eram aposentados, um por idade e outro por problemas de saúde, um trabalhava em estabelecimento que cuida de cabelos, outro era massoterapeuta e terapeuta naturopata. Duas alunas cursaram o Magistério como opção de Ensino Médio e uma havia feito curso de Formação Pedagógica para Séries Iniciais. Apenas quatro alunos ainda moram com os pais e não possuem parcial ou completa independência financeira. Oito possuem filhos e sete são responsáveis pelo seu sustento. Quatro almoçam diariamente no Restaurante Universitário, três eventualmente. Somente quatro possuíam veículo particular, dois o dividiam com o cônjuge, sendo que apenas um tinha carro com modelo de fabricação recente. Somente dois alunos já haviam viajado ao exterior, sendo que apenas um saído da América do Sul. Não nos ativemos na contagem e classificação dos sexos, tendo em vista que as orientações e classificações de gênero, bastante variadas e por vezes imprecisas, não foram consideradas relevantes para a presente análise. 
o (des)envolvimento de três eixos: o da criação experimentadora que produz artefatos e/ou poéticas, a decodificação ou leitura, a qual pode envolver também fruições e experiências estéticas não codificadas e o eixo formativo, que implica a informação, e a contextualização de produções e leituras, estas pensadas sobre diversos vieses, não apenas os históricos e geográficos, ainda que esses sejam os mais usados.

Embora ainda inseguros em suas bases conceituais, é bastante comum alunos licenciados em Artes afirmarem que a arte é uma forma de expressão, um meio de expressão ou expressão de um sentimento, uma maneira de exprimir sentimentos e ideias, assertiva que vem sendo observada em 13 anos de atuação dentro de uma Licenciatura. As concepções expressivistas muitas vezes se misturam com conceitos de arte como mediação entre instâncias, a arte significa o sentimento do artista com relação ao mundo, algumas delas envolvendo perspectivas mais amplas, como no depoimento que diz que a arte é expressão ao mesmo tempo consciente e inconsciente. Inconsciente, aqui, compreendido como própria essência incompreensível do sujeito, discurso com bases psicanalíticas obscuras, mas que se afirmou contundentemente pelo senso comum do século que nos antecede. Ao compreenderem que a arte é reflexo de um sentimento, o que mostra sentimentos, demonstra subjetividade, o discurso em vigor no início do século $\mathrm{XX}$ ainda é percebido. Quanto ao que entendem como subjetividade, é sempre algo de ordem interior, inconsciente, pessoal, algo posto como a necessidade da gente se conhecer, se individualizar, jamais o lugar dos sujeitos nas redes de saber e poder que os consistem, tal como demonstram os estudos de Foucault (2010) e produções que o precedem, as teorias pós-estruturalistas, em especial os Estudos Culturais. A separação entre subjetividade e a realidade exterior ao sujeito também aparece nas concepções em relação ao ensino, quando, por exemplo, um participante diz que ensinar é descobrir, trocar, estimular relações entre teoria e prática, fazendo conexões entre o mundo subjetivo e o mundo real. Essa noção de subjetividade se estende a uma concepção de arte em relação ao "eu criador", estereotipado no famoso ego do artista. Nesse sentido, a arte é o que o media visões subjetivas em relação a um mundo, neste caso, algo externo ao "eu". Tal concepção leva a ideia de que arte desenvolve uma forma de autonomia, desenvolve autossuficiência, assertiva que traz um ponto de vista não heteronômico, que tende a uma posição discursiva arraigada à 
razão de um sujeito soberano. Uma vez sendo trabalhado, em sala de aula, o conceito de heteronomia (LARROSA,2002, p. 28) é possível mostrar que as relações entre um corpo que se entende como "eu" e um mundo infinito, são deveras complexas para serem apenas mais um pretexto para arte. Mesmo assim, a arte ainda é considerada elemento formador crítico e de opinião, apesar desse discurso não pretender, de modo algum, defender a arte como tábua salvacionista. Desenvolvo livros de artista e autorretratos para dizer EU EXISTO, falou um dos participantes.

Existir um eu é uma das maneiras que o pensamento ocidental achou para justificar a permanência de um discurso, construção de uma língua para afirmar as identidades, perpassadas enquanto falas e grafia em dadas paisagens subjetivas. Lugares discursivos exprimem aquilo que se afirma como a verdade, as crenças e cultos de um povo, a maneira como esse possui para se colocar como força em dado tempo e determinado espaço. Tanto, que a arte pode ser entendida como produto de uma época, representação de uma época, algo que constitui registro de um momento histórico. Ao se compreender a produção artística como reflexo de um tempo, delegase à arte cadeias cronológicas e espaciais que a inserem em realizações culturais. Como escreve uma participante, arte é cultura em estado de condensação. Ação comum de um povo: arte. É nessa perspectiva que temos uma concepção bastante usada, apresentada por grande parte dos participantes e ainda presente em textos recebidos hoje em sala de aula, quando solicitadas concepções individuais de alunos: a arte é veículo de comunicação, forma de comunicação, ou, de um modo elaborado na escritura de um dos participantes: construção de elementos estéticos feitos pelo homem e que funcionam como forma de comunicação entre os indivíduos. De qualquer maneira, os enunciados problematizam as acepções demasiados diretas, de modo a um deles afirmar que a arte existe enquanto comunicação, mas não é comunicação.

Depois de uma formação em Desenho de Moda, onde a arte era vista como comunicação, uma das participantes relata que ampliou, na formação em Artes Visuais, a concepção adquirida na faculdade cursada anteriormente para o entendimento de arte como percepção, algo que envolve um sentir e todo um imaginário. Como legado imagético, ou imaginário expresso, a arte também é 
considerada "conhecimento". Defender a arte como "forma de conhecimento", tal como nos deixa o legado do DBAE e sua premissa canibalizada, como estratégia política para o ensino de Artes, pela Abordagem Triangular, é uma das afirmações mais usadas atualmente dentro do campo constituído pelas Artes na Educação. Tal enunciado advém da necessidade de legitimar as disciplinas artísticas nas instituições escolares e nos currículos. No discurso vigente, muito se diz sobre a arte ser um conhecimento tão importante quanto todos os outros.

Quando questionados sobre o que entendem como conhecimento, os participantes responderam tudo o que se sabe, o que existe para se conhecer, aquilo que tem valor na cultura, o que o homem comunica, o que foi construído no pensamento. No movimento onde uma definição implica a formulação de outras, um participante conclui que a arte é uma forma de pensar. As diferenças entre conhecimento e pensamento, todavia, ainda não se apresentaram desenvolvidas. $O$ artista pensa, e assim de alguma forma se posiciona diante do mundo em que vive, e isso estará impresso em seu trabalho, consta um depoimento. Impressão de posições no mundo, é inviável tomar a arte como instância transcendente ou ainda puramente física. No último encontro, acrescentei uma questão referente à natureza da arte, em que plano abstrato a situavam, que qualidades essenciais a ela atribuíam. Dentro de um consenso, o grupo concordou que a arte não distingue planos, intensifica o material e exprime forças metafísicas. Como escreve um aluno: tem a ver com o espírito porque é feita de matéria mas a ultrapassa e afunda em mistério. Arte trata daquilo que se estranha. Morte, amor, temores dos mais diversos. E também do que é pequeno, irrelevante e prosaico. Ao se tratar a Arte, mais do que forma de conhecimento, mas movimento do próprio pensar, podemos compreende-la como algo que imprime certa força, seja na parede de uma caverna ou no chão das ruas. Compreensão que extrapola a ideia de conhecimento como acúmulo de informações, interpretação corroborada dos fenômenos, ciência empírica, junção de textos canonizados ou outras imagens dogmáticas de pensamento. Formas de pensar que procuram extrair uma verdade absoluta de qualquer tipo de saber, de preferência saberes legitimados institucionalmente, uma imagem codificada. Por outro viés, ao imprimir forças que criam novas paisagens, a arte é uma ação do desconhecido, não codificado ou em vias de se transformar em novo código. De fato, há os que traduzem 
arte como algo indefinível, aquilo que me toca, dando mais nitidez ao conceito de estética. Neste aspecto, a necessidade de sair do comum é o que movimenta a arte em todas as suas manifestações. Tais acepções, em sua totalidade intuitivas, permitem que uma licencianda, já bacharel, diga que é impossível fazer arte sem romper com alguma ideia. Fazer arte, experimentar outro modo de enxergar o mundo, mesmo em suas repetições e apropriações é pressupor que, quando um pensante desconhece a gênese do que seu discurso afirma, mesmo quando esse mundo criado pelo pensamento rompe com as imagens pré-estabelecidas, as formas permanecem. Como se engendram constantemente novas formas junto às formas estabelecidas, pode-se, sem definir nenhum conceito final, que a arte funciona como o motriz intrínseco de toda diferença.

Arte, mais do que um conceito, é exatamente uma prática que impele à criação de conceitos. Ao invés de perguntares “o que é arte?", devias perguntar, "por que é arte?”, provocou uma participante. A arte se torna algo ou deixa de ser algo de acordo com justificativas que mudam conforme a posição, mas todas envolvendo pontos de vista fundamentais dentro de qualquer tipo de aula: mediação, comunicação, expressão, conhecimento em jogo, matéria, sentimentos.

\section{Práxis em sala de aula}

Nas enunciações apresentadas podemos detectar resquícios de ideais educacionais libertários, da pedagogia construtivista, do formalismo e da teoria crítica, imiscuídos a princípios esparsos da Abordagem Triangular. Embora seja senso comum que o ensino de artes nas escolas não tenha a meta de formar artistas e sim de desenvolver o um olhar crítico em relação às produções do mundo, ainda há poucos questionamentos em relação às suscetibilidades políticas em torno do ensino de artes e, principalmente, compreensão das bases epistemológicas que engendram práticas e discursos reproduzidos nos cursos de formação e em documentos referentes a prática pedagógica escolar. "A falta de preparação pessoal para ensinar artes é um problema crucial" (BARBOSA, 1998, p. 17). Assim que entram em sala de aula os alunos, em especial os bacharéis, os que nunca atuaram em escolas ou junto a grupos infanto-juvenis, observavam as abissais diferenças entre os campos investigativos da Arte e da Educação. Numa pesquisa em poéticas visuais o aluno 
precisa apenas se ocupar com as questões que seu trabalho individual coloca, sejam de âmbito técnico ou conceitual. Quando em sala de aula, percebem que o andamento de um projeto não depende apenas daquele que cria artisticamente, mas também de todos os agentes envolvidos no processo. Aquilo que selecionou para ser ensinado precisa fazer sentido para os alunos imbricados na ação. Daí a importância das escolhas na hora de traçar um projeto de ensino. Muitas vezes é dificílimo, para artistas que se tornam professores, pautar estas escolhas em função das heterogeneidades coletivas e singularidades comunitárias, as quais fogem aos seus critérios pessoais. Escolhas temáticas só terão sentido se dialogarem com universos de referência do grupo junto ao qual o projeto se desenvolve. Produções contemporâneas e a situação da produção artística são tópicos que se destacam na tomada de decisões do que se trabalhar em sala de aula. Articulando problemas à situações vividas no contexto específico para o qual foi criado, um projeto de ensino em Artes tende a produzir novas maneiras de pensar a arte e aquilo que os alunos vivem e criam. Professores-autores capazes de criar conceitos em sua práxis fazem de projetos pedagógicos, desenvolvidos em estágios docentes, oficinas e outros espaços, experiências de criação poética. Envolvem a potência dos grupos para os quais são planejados, num exercício de vontade que celebra a vida. Uma vida que não se apoia em ideais abstratos, mas se afirma nas criações conjuntas de um professor com os alunos que com ele percorrem períodos letivos.

Se ensinar artes é afirmar arte em ato artístico, mais do que dar aula sobre arte ou ensinar alguma técnica artística, desenvolver uma arte é ato talvez mais pedagógico de que a arte posta em um procedimento de ensino. Pesquisar a produção contemporânea é trazer ao público criações advindas de espaços e grupos junto aos quais a educação e a arte se cruzam. Nesse âmbito, pensamos a instituição e dificuldades em sala de aula. Lidamos com o contemporâneo no cotidiano de sala de aula, afirmando o processo ao invés do resultado, a experimentação no lugar da conclusão. Conceitos dos autores da Filosofia da Diferença mostram uma grafia, extraindo dos fatos algum registro, problematizando a permanência do texto pedagógico na afirmação das forças micropolíticas da arte. 


\section{Crítica cítrica ${ }^{4}$}

Traço aqui alguns apontamentos a fim de que possamos pensar o sentido de se deglutir determinados discursos, em especial aos advindos do texto pedagógico, que circulam em várias linhas e as implicações de suas múltiplas entrelinhas. Os atravessamentos nos discursos pedagógicos são tantos que é impossível abarcar todos os desdobramentos que provocam em um só estudo. Misturar perspectivas teóricas e fazer uma sopa heteróclita em torno de textos que, em outros âmbitos, discordam, parece paradoxalmente potente para pensarmos o que se faz em sala de aula. Os recortes enunciados têm 0 intuito mostrar forças discursivas antropofagizadas que implicam práticas em sala de aula, modificando a situação das artes na educação básica. A devoração de tantas referências pode produzir falta de relações adequadas, mal estar perante o sistema educacional e indigestão dos desnexos que encontramos na produtividade acadêmica (MACHADO; BIANCHETTI, 2011). Nem tudo o que entra no corpo o alimenta e tudo pode se tornar insustentável nessa vida de poucos rendimentos num mundo que visa lucro, no qual o magistério e as atividades acadêmicas são justificados pela vontade e não pelo retorno financeiro. Sermos bombardeados com várias questões impossíveis de serem aprofundadas e muitos lugares comuns do que se fala sobre arte, educação, estética e poética é o mais notável dos sintomas desta insustentabilidade. Saber que o que a escola requer, a que tipo de anseios as pesquisas respondem, o que se espera de um texto debatido e discutido em espaços de propagação do conhecimento no campo da educação e arte, como os educadores se relacionam com a arte e como "leem" o mundo, são, entre muitos outros, tópicos reiterados. Todos esses trazem elementos mais do que suficientes para se compreender um campo nem sempre específico, visto ser perpassado por saberes de todas as áreas de conhecimento. O que aqui se apresenta se dá por meio de um excesso de discursos que, por ironia, vão tornando a vida cada vez mais insana, ou seja, insustentável em termos de tranquilidade, fruição e partilhas. $\mathrm{O}$ que aqui podemos analisar se faz ver numa prática metodológica divorciada dos autores que fundam o discurso sobre o qual pesquisas se desenvolvem, sendo que

4 Aqui jogo com a escrita fragmentária da tese de uma professora de Ciências intitulada Palavra cítrica (JACQUES, 2011), a qual, até o momento da defesa, foi lida por mim como "crítica". 
acaba por se pautar em termos clichês e não em bases epistemológicas. Os rizomas, tão em voga e na moda, raramente são estudados junto ao texto de Mil Platôs e a totalidade da obra que engendra essa conceituação, de modo que acabam se reduzindo a uma imagem estereotipada e deslocada de seus autores para compreensão da complexidade de seu modo poético assumido como expressão. Temos que estar atentos para não provar discursos assumidos de um jeito leviano e inconsequente, sendo cada vez seja mais corriqueiro encontrarmos enunciados que pouco se articulam teoricamente, colados de modo a não expressarem os estudos aprofundados e as extensas pesquisas das quais originaram. Mas também há que se combater um sistema marcado pela rigidez das disciplinas, cuja avaliação e funcionamento não aceitam hibridismos, práticas coletivas e junção com a Terra. Isso motiva, contra toda sanidade necessária, a devorarmos autores não ortodoxos a fim de romper com compartimentos que tentam colocar a arte em caixas instransponíveis. Para uma formação de professores capaz de conduzir projetos de ensino efetivamente poéticos em todos seus aspectos triangulares e em todas as hexagonais produzidas nesta combinação é preciso de deixar perpassar por riscos, danças, cantos, jogos de palavras, pinturas, intervenções, ambiências. A prática docente se firma em determinados discursos, mas precisa assumir a criação de projetos e aulas transformando o que enuncia em torno da arte em criação de novos conceitos. Se operar com conceitos permite a criação e não a mera repetição de uma prática estabelecida. Porém, toda e qualquer criação corre o risco de se amalgamar em discurso respaldado por forças outras, tornando a potência do conceito uma mera reprodução.

O problema é a transcendência, a qual desloca a análise empírica, imanente ao campo pesquisado, para ideais, em especial os científicos. Ao elencar paradigmas para tratar dos deslocamentos de perspectivas, há que se cuidar que os centros paradigmáticos não sejam tomados como ideais transcendentes, pois onde pressupomos um centro criamos uma força, e onde uma força se acumula corremos o risco de criar uma moral a ser tomada como lei. A insustentabilidade de nosso modo de vida envolve os modos pelos quais tomamos a jurisprudência que as centrais de poder, especialmente aquelas respaldadas por discursos legitimados, exercem sobre nossa vida. Não podemos deixar que ações, convicções e valores se tornem uma 
moral, uma assertiva que nos engesse, nos amarre e nos impeça de inventar nossas aulas. Contra todo sistema de jurisprudência, a vida, e a natureza a ela imanente com toda sua profusão de variedades singulares, insurge algo que não podemos situar nem acima e nem abaixo das leis e compreensões humanas: poesia.

Descartes não desconhecia o poético como única verdade que alguém, entregue às forças da natureza; podia reconhecer como absoluta, na medida em que alega que "conduzimos nossos pensamentos por diversas vias e não consideramos as mesmas coisas" (DESCARTES, 2009, p.5). Uma crítica à visão cartesiana de mundo deve ser pautada nos modos pelos quais o método de Descartes acaba sendo tomado como o "certo". Por outro lado, tomar seu cientificismo como algo a ser combatido é desconhecer a fabulação assumida pelo próprio Descartes em seu Discurso sobre o Método, cujo propósito não é ensinar como cada um deve seguir a razão e sim "mostrar de que modo procurei conduzir a minha" (DESCARTES, 2009, p.9). Escrevendo em francês, não aceito pelas incipientes Academias do século XVII, pois não dominava a língua culta de sua época, sem pretensões Descartes cria o que posteriormente a Ciência assume como "caminho" para obtenção de verdades. Ao nos ocuparmos com as concepções canibalizadas em si, não nos embrenhamos em estudos dos significados, nem estudos para compreensão, tampouco em análises interpretativas. Não se trata de se preocupar com o que é o mais ou menos adequado, com o mais ou menos significativo, o mais ou menos inventivo, com isso ou aquilo. $\mathrm{Na}$ arte, ciência sem verdade, as coisas são isso e aquilo e mais aquilo e menos isso. Uma vez artistas, uma vez professora e artista, fica difícil defender um ponto de vista que outorga como verdade "isso tem a ver com isso, aquilo é representação disso e patatá", ou pior, "arte é isso, arte é aquilo".

\section{Pedagogia do conceito}

No capítulo Geofilosofia, em sua última obra em conjunto, Deleuze e Guattari escrevem sobre a reterritorialização da filosofia nos Estados democráticos e nos direitos do homem. O pensamento é nômade, vem sempre do caos e funciona como máquina de guerra, potência bárbara desterritorializante que investe contra o dado, o estabelecido e o conhecido. Como "pensar se faz antes na relação entre o território e a terra" (DELEUZE; GUATTARI, 1992, p. 113), criamos os conceitos para 
reterritorializar a selvageria do pensamento. O devir dos conceitos forma o plano de imanência filosófico. A formação dos conceitos acontece por hábito, há toda uma pragmática que funda os conceitos no plano e dá consistência ao pensamento. Os conceitos reterritorializam o pensamento radical e fazem a filosofia se conformar ao "espírito de um povo e sua concepção de direito" (DELEUZE; GUATTARI, 1992, p.134), descrevendo os modos particulares pelos quais a práxis cria planos conceituais. Os Estados nacionais possuem caráter filosófico específico: com um direito de costume, adquirido, o inglês faz as leis de pensamento por convenção, o francês opera por contratos e o alemão, historicista e territorial, institucionaliza. A partir do plano de imanência da Grécia Antiga, Inglaterra, França e Alemanha são eminentemente os países da História da Filosofia. Itália e Espanha são consideradas por Deleuze e Guattari nações cujo conceitualismo compromissado com a religiosidade produz valorosas figuras estéticas, mas são nações sem tradição filosófica, pois desviam os conceitos para artifícios de retórica.

As considerações geofilosóficas de Deleuze e Guattari giram em torno do europeu ocidental, o "Homem por excelência". Embora já se tenha abandonado a imagem do "selvagem" em contraposição ao europeu civilizado, o absolutismo das tradições europeias ainda causa a impressão de que a filosofia dificilmente é reterritorializada em outras nações. Ao construir um plano conceitual brasileiro, procuramos enxergar que tipo de hábitos e práticas reterritorializam o pensamento de pensadores estudados no Brasil. Será que sempre selvagem e desterritorializado, o pensamento brasileiro permanece sem direitos? A supremacia da colonização ibérica supõe que, como os espanhóis e os italianos, o pensamento brasileiro tenha a tendência de criar mais figuras estéticas do que personagens conceituais? Sem dúvida, partilhamos do sistema dedutivo dos franceses, da totalidade orgânica dos alemães (DELEUZE; GUATTARI, 1992, p. 137) e também nos apropriamos dos conceitos da mesma maneira como fazem os ingleses, mas, certamente, o plano sincrético do pensamento brasileiro tende mais para as composições da arte do que para os conceitos filosóficos. Embora tenhamos digerido muitos franceses, tal qual os extintos Tubinambás, temos devorado tantos povos em nossas leituras e assimilações culturais que é complicado compreender o que pensamos nós nesse imenso território. Tomando a leitura e a absorção de autores de modo fisiológico, podemos 
compreender o pensamento brasileiro, antropófago, na borda dos planos de imanência estratificados. Sendo um pensamento-corpo, consideramos a relação alimento-intelecto como nosso cerne geofilósofico, observando que "a marginalização da comida e do paladar no pensamento filosófico ocidental é muito reveladora quanto aos sentidos atribuídos ao gosto estético, à distância estética e à delimitação do campo da arte" (KEMPINSKA, 2016, p.8). Não existe uma "filosofia brasileira" mundialmente constituída, mas sim o impacto de uma cultura popular abundante, que fomenta criações musicais, artísticas, literárias. Os intelectuais-artistas brasileiros ganham o mundo 5 com arte. Proporcionalmente, o Brasil produz mais arte do que teoria. O pensamento dos intelectuais brasileiros, cujos movimentos começam no início do século $X X$, surge junto com criações artísticas e manifestações de cunho estético, como podemos atestar, especialmente, à semana de Arte Moderna de 1922. Há mesmo uma nítida tendência nas produções teóricas nacionais, mesmo que embasadas por autores franceses, alemães, ingleses e norte-americanos, a pensar os hábitos e os artefatos culturais dos inúmeros povos que nos vastos territórios brasileiros se cruzam.

Todo conceito pode apresentar figuras pitorescas para se exprimir. A diferença entre as figuras estéticas e os personagens conceituais não se dá porque as primeiras tendem a ser jogadas na noite irracional da simbologia, enquanto o conceito recebe "os prestígios da razão" (DELEUZE; GUATTARI, 1992, p. 120). Atingir a figura é trair a filosofia, é transformá-la em crença, religião, arte e idolatria, é fazer dos conceitos, transcendência. Transcendente, a figura é "paradigmática, projetiva, hierárquica e referencial"(DELEUZE; GUATTARI, 1992, p. 118), criada no plano de composição da arte e no plano de referência da ciência. A figura dobra-se à imanência do conceito e, retorcida, barroca, insufla o sublime no conceito. Territorial, plurívoco e sintagmático, o conceito conecta, conjuga outros conceitos, abandona as referências projetivas e estabelece um fundo uniforme de relações de vizinhança com outros conceitos.

5 Aqui, cabe lembrar que um dos poucos teóricos brasileiros, cuja obra é difundida internacionalmente, é Paulo Freire. Embora não existam referências suficientes para a constituição de uma filosofia brasileira, há uma "pedagogia brasileira", mesmo que com nítidos traços freirianos, mundialmente reconhecida. 
Povoado de sabedorias e religiões, o brasileiro pensa por figuras. Folclórico, carnavalesco, o pensamento brasileiro mistura elementos da natureza, zodíacos, ícones cristãos, arabescos barrocos, divindades clássicas, adereços tupi-guarani, menorás judaicas, mandalas hindus, hexagramas chineses, mesas brancas, sessões espíritas e congás cheios de santos, nossas senhoras e deuses africanos. Tanto nativo como colonizado, sempre mestiço, o pensamento brasileiro se faz por devoração; o sincretismo brasileiro é mais do que mistura, é antropofagia ${ }^{6}$. Ao constituir um plano conceitual que sirva para pensar os problemas da arte e da educação no Brasil, trabalhamos com pensamentos devoradores, alimentados por autores europeus e pelas digestões teóricas desses feitas por autores brasileiros. $\mathrm{O}$ plano de imanência do Ensino da Arte é uma degustação das mais diversas manifestações da arte e suas deglutições por artefatos populares, de disseminação generalizada. Exuberante, não é um campo anoréxico; sua maneira de escapar às normas do consumo não implica em privações e regurgito, mas sim num outro tipo de política, mais ligada à experimentação e à provação de sabores do que à falta de apetite teórico e à miséria estética.

Contra a inanição cultural das artes nas instituições escolares, as proposições em torno do que Ana Mae Barbosa formulou, combatendo às inércias do ensino de arte, circulam há três décadas. Porém, ainda não encontramos sua ampla formulação epistêmica assimilada nos enunciados de licenciandos e professores de arte na escola básica, apenas resquícios discursivos. Aqui não explanamos as bases teóricas que envolvem certos enunciados, pois, ao trazer recortes de enunciações mostrando as diversas concepções de arte, o intuito é movimentar suas complexas relações. Apesar disso, o trabalho desenvolvido durante os encontros com os participantes da pesquisa elucidava quais correntes metodológicas e contextos históricos se implicam em cada uma das concepções detectadas. $\mathrm{Na}$ apresentação de tais acepções, entre todos os enunciados, uma abordagem antropofágica das múltiplas combinações entre produzir, fruir e compreender vai sendo elaborada e pensada junto a perspectivas filosóficas

6 Não abordarei a ampla produção teórica sobre antropofagia, porque este artigo focaliza o ensino de artes. A maior parte dos estudos sobre antropofagia está prioritariamente vinculada ao campo da Literatura Brasileira, principalmente no Brasil, embora o tema apareça em estudos de antropologia e história. Cf. ALMEIDA. Tornar-se Outro: o topos canibal na literatura brasileira. São Paulo: Annablume, 2002. 
que inicialmente não a embasaram. Considerando que "em arte e em educação, problemas semânticos nunca são apenas semânticos, mas envolvem conceituação" (BARBOSA, 1998, p. 33), sem procurar extrair uma verdade dos enunciados, reforçamos o perspectivismo dos conceitos implicados na prática, trazendo algumas enunciações para melhor exemplificar os discursos que perpassam o campo da arte e seu ensino. Permeando esses modos de entendimento, há compreensões da arte como meio privilegiado de se viver experiências, das mais variadas: através da arte podemos nos comunicar, dar sentido a sensações, sentimentos e pensamentos. Temos a oportunidade de estimular nossa capacidade afetiva, intuitiva, estética e cognitiva. O participante que escreve tais linhas constrói um conceito de arte em que diversas perspectivas e planos filosóficos se misturam de maneira que a arte abarque o máximo de faculdades.

\section{Comilança residual}

A experiência mostra que grande parte dos resultados de uma investigação nos leva para outros pontos que não apenas os elencados na pesquisa. Relatórios de atividades, documentos fundamentais no registro dos processos, atestam a miríade de produções realizadas no ambiente escolar e a natureza diversa dessas em relação a projetos estritamente acadêmicos, os quais tentamos articular, algumas vezes artificialmente. O que se conclui é que problemas filosóficos e conceituais não estão apartados da práxis institucional, especialmente na complicada costura entre a escola básica e a vida acadêmica permeada pela produção intelectual. Os modos como essa produção adentra nas práticas discursivas dos docentes e como uma construção teórica vira uma palavra de ordem ortodoxa (ZORDAN, 2011), embora impliquem assimilações, não podem ser pensados como antropofagia. Uma estratégia de criação intelectual frente aos problemas encontrados não pode ser confundida com a deglutição de resquícios teóricos que se sedimenta em procedimentos reproduzidos repetidamente.

No mundo contemporâneo observamos facilmente o quanto a arte e os docentes encarregados dela nas escolas nunca estiveram tão próximos, de diversos modos, das bordas residuais do que a sociedade produz. Matéria passível de ser reciclada, mote para vários tipos de produção, especialmente as artísticas, pensamos 
e criamos com resíduos. Uma instalação de Michael Landy, Art Bin, na South London Gallery, em 2010, é exemplo notório de uma obra que, com o conceito de lixo, questiona os próprios valores da arte, numa espécie de exposição de fracassos em objetos e pinturas descartados por artistas de renome, como Damien Hirst. Matéria ou conceito, os resíduos que tomamos como lixo são matéria, concepção de lidarmos com os materiais e modo de vida. Continuemos, pois, a produzir lixo. Não obras rejeitadas, como as colocadas na instalação de Landy, mas objetos descartados por todos nós por serem impróprios ao uso (fabricados sem qualidade de material e com pouco cuidado). Em seu movimento de construir e descontruir, a arte tende a criar mais paradigmas e dogmas que a própria ciência, sendo que seu diferencial é apenas em relação aos compossíveis que desloca. Os conceitos são criações que movimentam os campos problemáticos que o pensamento atravessa. Para usar conceitos temos que desenvolver procedimentos de estudo e leitura daqueles autores escolhidos para nos acompanhar junto a tarefa de colocar um problema.

Procuramos modos de capturar a vida e dispor as imagens com as quais no acercamos do mistério da matéria no plano, expondo o resultado de nossas descobertas e novas criações para o mundo. Essas criações extrapolam as fronteiras da educação com a arte junto a uma educação em vias de se fazer, a qual se confunde com o plano de composição da arte. Não interpretamos as enunciações sobre Arte, mas efetivamos a arte em projetos políticos pedagógicos junto a intervenções poéticas e estéticas que constituem material para escrita acadêmica, documentando, em portfólios e textos específicos, descobertas frente a cada situação na qual nos deparamos. A partir de uma superação do que se diz e se concebe em termos de arte, na acepção da menina que diz ser a arte "mais antiga que o mundo", afirmamos o FRAGIL como modo de operar em instituições "duras".

A antropofagia, imanente ao devir das propostas e abordagens para o ensino da Arte, transgride qualquer fronteira e distorce qualquer tentativa de se estabelecer identidades fechadas, nacionais, de classe, de categoria: artista ou professor ou cientista. Sem fronteiras, temos um espaço expatriado, ao qual Deleuze e Guattari se referem quando falam do país da arte e da filosofia, terra ocupada por uma raça "que não se pretende pura, mas uma raça oprimida, bastarda, inferior, anárquica, nômade, 
irremediavelmente menor" (DELEUZE; GUATTARI, 1992, p. 141). É para esse povo ambulante, desatrelado de nações, gêneros e classificações, que Deleuze, algumas vezes junto a Guattari, traça sua filosofia, cujo plano de imanência não tem nada para se compreender ou interpretar (DELEUZE; PARNET, 1998, p. 12). Os conceitos desse plano, intensidades ópticas, dérmicas, sonoras, precisam ser experimentados e vividos, sentidos na pele, na carne e nos ossos. Imiscuir a arte no conceito é uma espécie de transgressão na História da Filosofia.

Na tentativa de exprimir uma síntese, fazer arte é uma maneira de ensinar e aprender o que pode vir a ser arte, afirmando a pesquisa em arte e educação como CRIAÇÃO que atravessa todo tipo de conceito. Tem o corpo e outras invenções daqueles que dela participam como realização efetiva daquilo que investiga, dialogando com licenciandos, coletivos de artistas, obras propositivas e produzindo arquivos que envolvem instalações, performances, tatuagens, pinturas em tela, intervenções em espaços institucionais, escolas, hospitais e campi. Trabalha-se, em suma, com o questionamento do que faz uma produção considerada artística se tornar ou não obra, uma formulação epistêmica virar, ou não, metodologia, um discurso estar, ou não, perfazendo práticas.

Motivados em experimentar o novo, em ativar o sentido de suas práticas cotidianas (tais como atendimentos de alunos, formação continuada com professores e interação com o público em geral) aqui, a Abordagem ou Proposta criada por Ana Mae Barbosa se dá numa via antropofágica. Em seus múltiplos usos, pensamos o fruir, o contextualizar e o criar através de proposições coletivas de investigação, assumindo o perspectivismo nietzschiano para afirmar uma Vontade de Arte. Querer fazer arte é mais pedagógico do que tentar ensiná-la. A afirmação dessa vontade é distinta do saber que acompanha a instituição da educação escolar e as escolhas curriculares de praxe. É uma vontade de poder que, ao não poder nada, ultrapassa a Vontade de Nada, niilismo reativo, para exercitar potências e fazer valer forças salutares de vida. A potência está justamente em aceitar a existência em seu aspecto mais escatológico, fazendo do fardo, dos fados, faires, feitos, criação. Ainda que frágeis, visto não terem grandes públicos, não estarem nas mídias e não terem impacto social além dos alunos listados em cada turma 
O que se aprende trazendo abordagens e propostas para uma instituição de ensino são as forças afetivas que nela, sobre o nosso corpo, fazem valer. Deleuze embasa o que já foi defendido em tese e experimentado empiricamente na pesquisa Potências das Artes Visuais em sala de aula: a arte ensina a pensar. Com a arte é possível sair do que o filósofo traz como os empecilhos do pensar: a reminiscência, a contemplação, a reflexão (como espelhamento teórico inócuo). Com a arte nos adentramos numa espécie de esvaziamento cheio de potências para novas criações intelectuais. Isso também é possível via filosofia, porém numa via restrita aos sábios amigos dos conceitos, exigindo daquele que acaba atravessado pelos afectos conceituais instrumentos mais complexos do que a simples abertura ao novo, a qual aquele que frui de uma criação artística precisa apresentar. Se essa abertura não ocorre facilmente não é um problema que concirna à "pedagogia do conceito" (DELEUZE; GUATTARI, 1992, p. 21) e sim às ditaduras da moral que condenam os movimentos que a arte provoca. Por isso a arte é sempre pedagógica, pois, aberta, dilacerada e marcada pelas sensações que a produção e a fruição trazem, é um corpo propício ao acontecimento de se aprender.

\section{Referências}

ANDRADE, Oswald de. Manifesto antropófago. Disponível em: <http://www.ufrgs.br/cdrom/ oandrade/oandrade.pdf>. Acesso em: 18 de fev. 2017.

BARBOSA, Ana Mae. Tópicos utópicos. Belo Horizonte: C/Arte, 1998.

DELEUZE, Gilles; GUATTARI, Félix. O que é a filosofia? São Paulo: Ed. 34, 1992.

DELEUZE, Gilles; GUATTARI, Félix. Mil platôs, v. 3. São Paulo: Ed. 34, 1996.

DELEUZE, Gilles; GUATTARI, Félix. Mil platôs: capitalismo e esquizofrenia, v. 5. São Paulo: Ed. 34, 1997.

DELEUZE, Gilles; PARNET, Claire. Diálogos. São Paulo: Escuta, 1998.

DESCARTES, René. Discurso do método. São Paulo: Martins Fontes, 2009.

FOUCAULT, Michel. Estratégia, poder-saber. Coleção Ditos e Escritos, v. 4. Rio de Janeiro: Forense Universitária, 2010.

GUATTARI, Félix; ROLNIK, Suely. Micropolíticas: cartografias do desejo. Petrópolis: Vozes, 1999.

JACQUES, Carmen Regina Reginaldo. Palavra cítrica. Porto Alegre: UFRGS, 2011. Tese (Doutorado em Educação) - Programa de Pós-Graduação em Educação, Faculdade de Educação, Universidade Federal do Rio Grande do Sul, Porto Alegre, 2011.

KEMPINSKA, Olga Donata Guerizoli. Leitura e suas metáforas alimentares. Leitura: Teoria e Prática, Campinas, v. 34, n. 66, p. 61-74, 2016.

LARROSA, Jorge. Notas sobre a experiência e o saber da experiência. Revista Brasileira de Educação, Rio de Janeiro, n. 19, p. 20-28, jan./fev./mar./abr. 2002. 
MACHADO, Ana Maria N.; BIANCHETTI, Lucídio. A (des)fetichização do produtivismo acadêmico: desafios para o trabalhador-pesquisador. RAE Eletrônica (on-line), v. 51, n. 3, p. 244-254, maio/jun. 2011.

ROLNIK, Suely. Cartografias sentimentais: transformações contemporâneas do desejo. São Paulo: Estação Liberdade, 1989.

ZORDAN, Paola. Potências das Artes Visuais em sala de aula. (Relatório Final de Pesquisa)184f. Porto Alegre: FACED/UFRGS, 2008.

ZORDAN, Paola. Imagem-Ordem: observações da Iniciação à Docência. 34a Reunião da Associação de pesquisa e pós-graduação em educação. Disponível em: <http://34reuniao.anped.org.br/images/ trabalhos/GT24/GT24-685\%20int.pdf>. Acesso em: 20 de fev. 2017.

\section{Paola Basso Menna Barreto Gomes Zordan}

Bacharel em Desenho, Licenciada em Educação Artística, Mestre e Doutora em Educação pela Universidade Federal do Rio Grande do Sul. Professora do Departamento de Artes Visuais da UFRGS. Na mesma instituição é professora do Programa de Pós-Graduação em Educação, na linha de pesquisa Filosofias da Diferença. Líder do Grupo de Pesquisa ARCOE: Arte, Corpo, enSigno (CNPQ), junto ao qual desenvolve pesquisas que envolvem poéticas no âmbito educativo, historiografia da arte e esquizoanálise. Trabalha com performances, escultura social e micropolíticas, criando intervenções em espaços públicos e institucionais.

E-mail: paola.zordan@gmail.com

Currículo: http://lattes.cnpq.br/4035205657093564

Recebido em 15 de março de 2017 Aceito em 18 de maio de 2017 